(DAS28), age, disease duration, CRP, IgM rheumatoid factor, anti-CCP and plasma lipid levels were also measured. Arterial flow-mediated vasodilation (FMD), carotid intima-media thickness (CIMT) and arterial pulse-wave velocity (PWV) were assessed by ultrasound.

Results: There were no significant changes in the levels of anti-hsp60, ADMA and BNP due to anti-TNF therapy. However, baseline level of BNP is strongly correlated with the levels of rheumatoid factor $(R F)(R=0.479, p=0.004)$ and cyclic citrullinated peptid $(C C P)(R=0.591, p<0.001)$. Serum BNP levels at baseline and at month 6 were significantly increased in RF positive compared to RF negative patients $(680.60 \pm 381.64$ versus $292.94 \pm 198.27 \mathrm{pmol} / \mathrm{L} ; \mathrm{p}=0.007$ and 668.95 \pm 346.51 versus $312.20 \pm 207.01 \mathrm{pmol} / \mathrm{L} ; \mathrm{p}=0.001$ ) and also in CCP postive compared to CCP negative patients $(670.61 \pm 323.04$ versus $137.98 \pm 436.41 \mathrm{pmol} / \mathrm{L}$; $\mathrm{p}=0.030$ and $652.93 \pm 283.21$ versus $456.48 \pm 423.11 \mathrm{pmol} / \mathrm{L} ; \mathrm{p}=0.021)$. Furthermore we found the following correlations between baseline values: anti-hsp60 level correlated with ADMA $(R=0.900, p=0.037)$, triglyceride $(T G)(R=0.462$, $\mathrm{p}=0.040)$ and $\mathrm{PWV}(\mathrm{R}=0.564, \mathrm{p}=0.040)$. Baseline level of ADMA positively correlated with body mass index $(\mathrm{BMI})$ score $(\mathrm{R}=0.720, \mathrm{p}=0.040)$ and also with HDL levels (high density lipoprotein) of patients $(R=0.473, p=0.047)$. Baseline level of BNP also correlated with triglyceride (TG) level $(R=0.377, p=0.036)$.

Conclusions: BNP levels were significantly higher in RF +compared to RFpatients, which imply that BNP may associate with RF positivity. Specific biomarkers, such as ADMA, anti-hsp60 and BNP may play important role cardiovascular disease in RA.

Disclosure of Interest: None declared

DOI: 10.1136/annrheumdis-2018-eular.2121

\section{FRI0058 $\quad$ SERUM AND SYNOVIAL SURVIVIN ARE ASSOCIATED WITH EROSIVE NOT ACTIVE RHEUMATOID ARTHRITIS}

E. Baraka, M. Serag El Din , A. El Shambky, M. Aboul Gheir. Rheumatology, Rehabilitation and Physical medicine, Benha Faculty of Medicine, Benha University., Cairo, Egypt

Background: Rheumatoid arthritis (RA) is a progressive debilitating autoimmune disease leading to cartilage and bone destruction caused by insufficient apoptosis in the inflamed RA synovium. Survivin is a proto-oncogene biomarker known for its anti-apoptotic and cell cycle regulating properties and has been linked linked to inflammation, presumably contributing to the decreased apoptosis in the T cells in non cancerous proesses.

Objectives: The aim of this study is to measure the serum and synovial levels of survivin and clarify their relations to disease activity, functional capacity and radiographic damage in RA patients.

Methods: This study was carried out on 50 RA patients ( $F: M=39: 11)$ had a mean age of $(46.4 \pm 10.94)$ years and 30 subjects of matched age and sex with a mean age of $(46.03 \pm 10.53)$ years and $F: M(23 / 7)$ as a control group. All patients were subjected to full history taking, thorough clinical examination, assessment of disease activity by DAS-28 score and functional capacity and using Health assessment Questionnaire (HAQ). Plain x- ray radiographs of both hands and feet were done, scored and graded by Larsen score. Survivin levels in all studied subjects' sera and the synovial fluid aspirated from 18 RA patients presented with knee effusion at the time of examination were measured by enzyme- linked immunosorbent assay (ELISA).

Results: The mean serum survivin level was highly significantly elevated $(\mathrm{p}<0.001)$ in the RA patients sera than in the controls' being $479.61 \pm 52.68(\mathrm{pg} / \mathrm{ml})$ and $239.1 \pm 115.15(\mathrm{pg} / \mathrm{ml})$ respectively. Synovial survivin levels ranged between $420-575(\mathrm{pg} / \mathrm{ml})$ with a mean of $479.61 \pm 52.68(\mathrm{pg} / \mathrm{ml})$ and was significantly higher than in the RA patients' sera $(p<0.001)$. RA patients were divided into survivin -ve group included $21 / 50(42 \%)$ and survivin +ve group included $29 / 50$ (58\%), the serum survivin cut off point $(167.63 \mathrm{pg} / \mathrm{ml})$ was selected at the mean plus 3 SD for the control group. Survivin+ve RA patients group have significantly longer mean disease duration and higher HAQ and larsen scores $(p<0.001)$ than survivin -ve RA patients group. 9/13 (69\%) of the RA patients with Sjogrene's syndrome, 8/10 $(80 \%)$ of the patients with pleural effusion, $3 / 6$ (50\%) patients with Raynaud's phenomenon, all patients with sc nodules $(5,100 \%)$, episcleritis $(2,100 \%)$ and vasculitis $(1,100 \%)$ were survivin +ve. RA patients who had Larsen score grading $\geq 2$ $(27 / 50,52 \%)$ were considered to have an erosive RA disease. There were no statistically significant differences between RA patients according to the presence of erosion regarding age, sex, VAS, DAS score, the presence of RF abs, Anti- CCP abs, mean HB\%, WBCs count, PLTs count, ESR 1 st hr value or CRP level. All RA patients with erosive disease were survivin +ve and had statistically significantly elevated mean serum and synovial survivin levels than the RA patients with non erosive disease $(337.37 \pm 55.19 \mathrm{pg} / \mathrm{ml}$ vs $126.78 \pm 24.33 \mathrm{pg} / \mathrm{ml}$ and 422.5 $\pm 3.53 \mathrm{pg} / \mathrm{ml}$ vs $486.75 \pm 51.52 \mathrm{pg} / \mathrm{ml}$ respectively)

Conclusions: High levels of survivin are detected in the blood and synovial fluid of RA patients and are associated with erosive joint damage and poor functional outcomes but not related to disease activity.

\section{REFERENCE:}

[1] Chen D, Liu D, Liu D, He M, Peng A, Xu J, Lin L, Luo F, Chen L, Huang X, Zhuang J, Xu J. Rheumatoid Arthritis Fibroblast-like Synoviocyte Suppression Mediated by PTEN Involves Survivin Gene Silencing. Sci Rep 2017;7(1):367.

Disclosure of Interest: None declared

DOI: 10.1136/annrheumdis-2018-eular.3974

\section{FRI0059 INTERSTITIAL LUNG DISEASE IN PATIENTS WITH RHEUMATOID ARTHRITIS OF A COHORT TREATED WITH METHOTREXATE MONOTHERAPY}

E. Chamizo-Carmona ${ }^{1}$, C. Carrasco Cubero ${ }^{2}$, S.M. Rojas Herrera ${ }^{1}$, J. Malave Calzada', R. Veroz Gonzalez ${ }^{1}$, L.M. Chaves Chaparro'. ${ }^{1}$ Rheumatology, Hospital Ciudad de Merida, Merida; ${ }^{2}$ Rheumatology, CHU de badajoz, Badajoz, Spain

Background: Diffuse interstitial lung disease (ILD) is a common extra-articular manifestation of rheumatoid arthritis (RA) and an important cause of morbidity and mortality in this patient population. The predisposing and prognostic factors of this complication are a matter of debate.

Objectives: To determine the characteristics associated with the development of ILD in a cohort of patients with RA who received Methotrexate (MTX) monotherapy. Methods: Case-control study in a cohort of patients with RA who had received MTX monotherapy, being cases those who developed ILD and controls, those who did not develop it.

Results: The cohort consisted of 301 patients ( $67 \%$ women), with a mean age of $49.6( \pm 13.2)$ years and a follow-up of $135.8( \pm 93.5)$ months. There were $15(5 \%)$ cases of ILD, classified by high resolution chest CT as usual interstitial pneumonitis 7 , nonspecific interstitial pneumonitis 7 and interstitial bronchiolitis 1 . The distribution by sex was 8 ILD among 202 women (3.9\%) and 7 ILD among the 99 men $(7.1 \%)$. They all had RF and/or ACPA positive. ILD was associated with longer duration of the disease $(p<0.05)$, exposure to DMARDs prior to MTX $(\mathrm{OR}=3.3, \mathrm{p}<0.05)$, history of chronic lung disease $(\mathrm{OR}=6.5 ;<0.01)$ and coexistence with secondary Sjögren syndrome $(O R=3.2, p<0.05)$. We did not find significant differences in mean values of age, RF, ACPA, baseline CRP and DAS28, dose, route and time of exposure to MTX, smoking, functional capacity, presence of erosions, MTX response and toxicity. The predictive factors in the logistic regression were the history of chronic pneumopathy, extra-articular involvement, time of evolution and basal biological activity (CRP) of the disease. Of the 15 patients with ILD, $5(33.3 \%)$ had good response (DAS28-CRP $<3.2$ ) with MTX and remained on monotherapy, another 3 continued with MTX combined with another DMARD and $7(46.7 \%)$ discontinued MTX. In addition, 8 of these 10 patients received a biological therapy. Eleven patients died during follow-up, $3(20 \%)$ cases (ILD) and $8(2.8 \%)$ controls $(p<0.01)$.

\begin{tabular}{lcccc}
\hline Clinical characteristics of the cohort & & & & \\
\hline & Total $(301)$ & $\operatorname{ILD}(15)$ & No ILD $(286)$ & $\mathrm{p}$ \\
\hline Age, years, mean(SD) & $49,6(13,2)$ & $53,5(13,9)$ & $49,3(13,2)$ & 0,23 \\
Women, $\mathrm{n}(\%)$ & $202(67,1)$ & $8(53,3)$ & $194(67,8)$ & 0,24 \\
RA Duration, months, mean(SD) & $135,8(93,5)$ & $105,0(27,1)$ & $92,4(5,5)$ & 0,04 \\
Smoker, n(\%) & $183(60,8)$ & $8(53,3)$ & $175(61,2)$ & 0,54 \\
Previous chronic lung disease, $\mathrm{n}$ & $51(16,9)$ & $8(53,3)$ & $43(15,0)$ & 0001 \\
(\%) & & & & \\
Sjogren síndrome, n(\%) & $33(11,0)$ & $4(26,7)$ & $29(10,1)$ & 0,04 \\
Previous FAME, n(\%) & $81(26,9)$ & $8(53,3)$ & $73(25,5)$ & 0,02 \\
CRP, mg/l, mean(SD) & $17,8(21,3)$ & $32,3(31,9)$ & $17,0(20,4)$ & 0,09 \\
DAS28-CRP, mean(SD) & $4,5(0,8)$ & $4,6(0,8)$ & $4,5(0,8)$ & 0,54 \\
RF, mean (SD) & 141,7 & 226,0 & 137,2 & 0,30 \\
& $(212,3)$ & $(314,1)$ & $(205,4)$ & \\
ACPA, mean (SD) & 156,4 & 198,3 & 154,2 & 0,31 \\
& $(156,7)$ & $(161,5)$ & $(156,5)$ & \\
MTX, mg/week, mean (SD) & $16,5(3,7)$ & $16,2(3,9)$ & $16,5(3,7)$ & 0,74 \\
MTX Response, n(\%) & $149(49,5)$ & $5(33,3)$ & $144(50,3)$ & 0,20 \\
Withdrawal of MTX, n(\%) & $71(23,6)$ & $7(46,7)$ & $64(22,4)$ & 0,03 \\
Deaths, n(\%) & $11(3,6)$ & $3(20,0)$ & $8(2,8)$ & 0001 \\
\hline
\end{tabular}

Conclusions: ILD is a frequent and serious complication in RA. It appears more frequently in patients with previous pneumopathy and long-term disease and with extra-articular involvement of RA.

Disclosure of Interest: None declared

DOI: 10.1136/annrheumdis-2018-eular.5495 